\title{
TRATAMIENTO DE LA VIOLENCIA DE GÉNERO EN LA PRENSA VASCA
}

\author{
María Pilar Rodríguez
}

\section{Resumen}

El presente artículo refleja los resultados del estudio desarrollado por el equipo de investigación Género y medios de comunicación del departamento de Comunicación de la Facultad de Humanidades de la Universidad de Deusto-San Sebastián, y se centra en el análisis del tratamiento de la violencia de género en los diarios más representativos de la prensa vasca en el período que va desde septiembre de 2003 hasta junio de 2004 (Berria, Deia, El Correo, El Diario Vasco y Gara). El estudio se basa en una muestra de 1337 textos periodísticos, y responde a la profunda convicción en la necesidad de buscar soluciones a una acuciante lacra social que se materializa en los asesinatos de un número elevado de mujeres a manos de sus compañeros sentimentales. Los resultados del análisis detallado de titulares, reportajes y entrevistas y periodismo de opinión el aportan una contribución para una mejor comprensión del fenómeno, lo que permite, en primer lugar, describir la situación actual en el panorama del periodismo en el País Vasco, y en segundo lugar, formular ciertas apreciaciones críticas encaminadas a la recomendación de procedimientos que contribuyan a las buenas prácticas periodísticas. Junto con las medidas legislativas, políticas, penales y educativas, imprescindibles para la futura y deseable erradicación de la violencia de género, los estudios centrados en los medios de comunicación constituyen una aportación necesaria por su gran influencia en la audiencia dentro de la vida cotidiana.

Palabras clave: violencia de género, prensa vasca, medios de comunicación, análisis del discurso.

\begin{abstract}
This article presents the results of a research project carried out by the Gender and Media research group at Deusto University in San Sebastián, and focuses on the analysis of the treatment of the subject of violence against women in Basque newspapers in the period between September 2003 until June 2004 (Berria, Deia, El Correo, El Diario Vasco y Gara). The study is based on a sample of 1337 texts and responds to the urgent need to find solutions to the extremely high number of women who die every year as a result of this kind of violence. The results obtained after the detailed analysis of headlines, interviews, editorial and other kind of articles and news help to understand the social and discursive constructions of media reports regarding violence agains women. The article formulates a number of reccommendations to
\end{abstract}


encourage jornalists and other media professional to provide a rigurous and fair treatment of such news in daily newspapers in order to help the dissemination of better practices regarding gender in daily life.

Key words: Violence against women, Basque press, media analysis, discourse.

\section{Introducción}

El presente artículo refleja los resultados del estudio desarrollado por el equipo de investigación Género y medios de comunicación del departamento de Comunicación de la Facultad de Humanidades de la Universidad de Deusto-San Sebastián, dirigido por la autora de este artículo y formado por Larraitz Ariznabarreta, María Jesús Korkostegi, María Jesús Pando y Begoña Sanz, y se centra en el análisis del tratamiento de la violencia de género en los diarios más representativos de la prensa vasca en el período que va desde septiembre de 2003 hasta junio de 2004 (Berria, Deia, El Correo, El Diario Vasco y Gara). El estudio se basa en una muestra de 1337 textos periodísticos, y responde a la profunda convicción en la necesidad de buscar soluciones a una acuciante lacra social que se materializa en los asesinatos de un número elevado de mujeres a manos de sus compañeros sentimentales. Dicho estudio se publicó en 2005 bajo el título Tratamiento de la violencia de género en la prensa vasca (Universidad de DeustoEmakunde), y se ha convertido en modelo de referencia para los medios de comunicación a partir de la recomendación del Parlamento Vasco. Como informa el diario El País en su edición del 16 de diciembre de 2007 bajo el epígrafe "La ponencia sobre violencia de género logra el acuerdo de todos los grupos", todos los grupos del Parlamento Vasco lograron acordar un informe centrado en el análisis de la violencia de género en Euskadi y plantear una batería de propuestas para avanzar en la igualdad de derechos entre hombres y mujeres, sensibilizar a la sociedad acerca del problema y mejorar la atención que las víctimas reciben de las administraciones. La noticia incluía la siguiente información: 
El informe, que se aprobará el miércoles, atribuye a los medios de comunicación una importante responsabilidad en la prevención de la violencia de género y plantea que dispongan de un comité que supervise sus contenidos para evitar mensajes sexistas y sigan las recomendaciones del libro Tratamiento de la violencia de género en la prensa vasca, de la Universidad de Deusto, a la hora de informar.

Es por ello que parece oportuno recoger aquí en forma resumida de artículo las principales aportaciones del libro mencionado. En efecto, los medios de comunicación, y la prensa escrita en particular, además de informar acerca de los sucesos que se producen, elaboran editoriales, incluyen artículos de opinión, entrevistas y reportajes, y de este modo los casos de violencia contra las mujeres adquieren una visibilidad mediática, y pasan de ser un asunto privado a convertirse en tema de tratamiento y debate público. Importa subrayar que los medios configuran la percepción de la audiencia de los casos acaecidos y moldean actitudes desde diversas posiciones ideológicas y éticas. Para un número elevado de lectores/as de prensa, el retrato informativo expuesto en los diarios se convierte en única fuente de conocimiento sobre esta realidad.

Por esta razón, el análisis del tratamiento de la violencia de género en la prensa vasca supone una pequeña contribución para una mejor comprensión del fenómeno, lo que permite, en primer lugar, describir la situación actual en el panorama del periodismo en el País Vasco, y en segundo lugar, formular ciertas apreciaciones críticas encaminadas a la recomendación de procedimientos que contribuyan a las buenas prácticas periodísticas. Junto con las medidas legislativas, políticas, penales y educativas, imprescindibles para la futura y deseable erradicación de la violencia de género, los estudios centrados en los medios de comunicación constituyen una aportación necesaria por su gran influencia en la audiencia dentro de la vida cotidiana.

El estudio parte de una reflexión desarrollada por el equipo en su conjunto acerca de la denominación violencia de género, ya que durante los meses que abarca el estudio se generó en la prensa escrita y en diversos medios de comunicación un debate 
metalingüístico centrado en la propia denominación del fenómeno que analizamos y más específicamente, en la conveniencia o no de utilizar el término "violencia de género".

Frente al rechazo mostrado por la Real Academia de la Lengua Española y otros grupos sociales en torno al uso de este término, nuestro grupo estudia las numerosas denominaciones existentes (violencia de género, violencia doméstica, violencia contra las mujeres, violencia machista, terrorismo doméstico, entre otras), y reivindica la primera por motivos de tradición teórica feminista. La significación de género desde esta perspectiva es compleja y enriquecedora, si bien resulta desconocida por ciertos estamentos de la esfera pública. El término "género" va más allá de la mera diferenciación biológica y hace referencia a las construcciones culturales, a la creación social de ideas acerca de lo que es apropiado y conveniente para los hombres y para las mujeres.

El concepto de género puede definirse como el conjunto de creencias, rasgos personales, actitudes, sentimientos, valores, conductas y actividades que diferencian a hombres y mujeres a través de un proceso de construcción social que tiene varias características. En primer lugar es un proceso histórico que se desarrolla a diferentes niveles tales como el estado, el mercado de trabajo, las escuelas, los medios de comunicación, la ley, la familia y a través de las relaciones interpersonales. En segundo lugar, este proceso supone la jerarquización de estos rasgos y actividades de tal modo que a los que se definen como masculinos se les atribuye mayor valor. Hay que añadir que para referirse a la violencia ejercida por el hombre contra la mujer, los Institutos de la Mujer y las asociaciones de mujeres prefieren la denominación "violencia de género" a otras. Dicha denominación fue acuñada oficialmente a partir de la IV Conferencia Mundial sobre la Mujer, celebrada en Pekín en 1995 y auspiciada por la ONU, y la Asamblea de las Naciones Unidas ofrecía la siguiente definición en 1993: "Violencia de género es todo acto de violencia basado en la pertenencia al sexo femenino que tenga o pueda tener como resultado un daño o sufrimiento físico, sexual o psicológico para las 
mujeres, incluidas las amenazas de tales actos y la coacción o privación arbitraria de libertad".

\section{Presencia de la violencia de género en la prensa vasca}

La violencia de género irrumpe mayoritariamente en las páginas de los diarios a través de noticias sobre agresiones cometidas por los maltratadores y sobre su detención. Tal y como se puede apreciar en la Tabla 1, en 1025 ocasiones los diarios recurren al género informativo para ofrecer datos sobre esta realidad, lo que supone el $76,6 \%$ de todo el material publicado; en 213 entrevistas y reportajes (16\% de los textos) abordan el tema de la violencia de género y se opina acerca de ella en 99 editoriales, columnas y viñetas editados por los diarios vascos. La noticia, por tanto, resulta el género más abundante.

Tabla 1: Género de los textos publicados

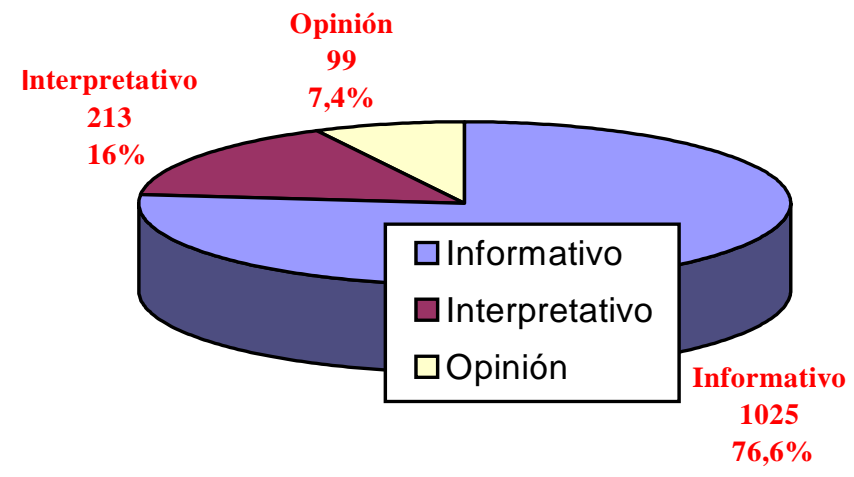


De las más de mil noticias impresas, como muestra la Tabla 2, el 48,6\% recoge hechos violentos protagonizados por el agresor, la mayoría con resultado de muerte para la mujer agredida, y/o su posterior detención. Esta tendencia se constata en todos los diarios analizados si bien Berria es el periódico que menos informaciones publica sobre delitos y detenciones y el que proporcionalmente más atención otorga a los temas políticos, legislativos, culturales y sociales. La supremacía de las noticias sobre delitos y detenciones no se halla de forma exclusiva en el tema de la violencia de género: responde a la importancia que los diarios conceden en su agenda informativa a este tipo de hechos. José Luis Dader, aludiendo a la teoría contemporánea de la noticia, establece que los criterios que priman entre los componentes de "una buena noticia" poco tienen que ver con epistemologías racionales de "relevancia social", "importancia objetiva", "gravedad", "instituciones o sociopolítica" y sí mucho más con puras pulsiones sensitivas ${ }^{1}$.

Tabla 2: Temas de las noticias

\begin{tabular}{|c|c|c|c|c|c|}
\hline TEMAS/DIARIOS & BERRIA & DEIA & EL CORREO & EDV & GARA \\
\hline \begin{tabular}{|l|} 
Delitos y detenciones \\
\end{tabular} & $\begin{array}{l}66 \\
38,6 \% \%\end{array}$ & \begin{tabular}{|l|}
125 \\
$47,53 \%$
\end{tabular} & $\begin{array}{l}111 \\
56,63 \%\end{array}$ & 102 & $\begin{array}{l}94 \\
50 \%\end{array}$ \\
\hline \begin{tabular}{|l|} 
Juicios \\
\end{tabular} & $\begin{array}{l}29 \\
16,96 \%\end{array}$ & $\begin{array}{l}38 \\
14,45 \%\end{array}$ & $\begin{array}{l}28 \\
14,29 \%\end{array}$ & 36 & $\begin{array}{l}41 \\
21,81 \%\end{array}$ \\
\hline $\begin{array}{l}\text { Aspectos políticos y } \\
\text { legislativos }\end{array}$ & $\begin{array}{l}22 \\
12,86 \%\end{array}$ & \begin{tabular}{|l|}
40 \\
$15,21 \%$
\end{tabular} & $\begin{array}{l}26 \\
13,26 \%\end{array}$ & 28 & $\begin{array}{l}11 \\
5,85 \%\end{array}$ \\
\hline
\end{tabular}

\footnotetext{
${ }^{1}$ Vid. DADER, J.L.: La “mujer” como categoría emergente en la producción de noticias: pros y contras de una nueva visibilidad periodística. Ponencia presentada en la Jornada sobre "Mujeres, Hombres y Medios de Comunicación" de la Dirección General de la Mujer, Junta Castilla y León. Valladolid, 23 de noviembre, 2000.
} 
Tratamiento de la violencia de género en la prensa vasca

\begin{tabular}{|c|c|c|c|c|c|}
\hline $\begin{array}{l}\text { Aspectos culturales y } \\
\text { educativos }\end{array}$ & $\begin{array}{l}16 \\
9,36 \%\end{array}$ & $\begin{array}{l}14 \\
5,32 \%\end{array}$ & $\begin{array}{l}8 \\
4,08 \%\end{array}$ & 12 & $\begin{array}{l}7 \\
3,72 \%\end{array}$ \\
\hline Aspectos sociales & $\begin{array}{l}35 \\
20,47 \%\end{array}$ & $\begin{array}{l}35 \\
13,31 \%\end{array}$ & \begin{tabular}{|l|}
21 \\
$10,71 \%$
\end{tabular} & 20 & $\begin{array}{l}33 \\
17,55 \%\end{array}$ \\
\hline Aspectos religiosos & 0 & $\begin{array}{l}2 \\
0,76 \%\end{array}$ & $\begin{array}{l}1 \\
0,51 \%\end{array}$ & 7 & $\begin{array}{l}2 \\
1,06 \%\end{array}$ \\
\hline Otros & $\begin{array}{l}3 \\
1,75 \%\end{array}$ & $\begin{array}{l}9 \\
3,42\end{array}$ & $\begin{array}{l}1 \\
0,51 \%\end{array}$ & 2 & 0 \\
\hline TOTAL & 171 & 263 & 196 & 207 & 188 \\
\hline
\end{tabular}

Las informaciones que contienen valores noticia como la violencia, la muerte, el crimen, el drama o el morbo fácilmente encuentran un hueco en las páginas de los periódicos debido a su impacto mediático. Y las noticias sobre maltratos reúnen varias de estas cualidades, en palabras de Dader, "de estos resortes clásicos de la apelatividad periodística" (2000: 24), que hacen que un suceso adquiera la categoría de noticiable. Resulta, por tanto, acorde con los criterios de selección de las noticias, la abundancia de informaciones sobre delitos y detenciones de los maltratadores en la prensa vasca. Los juicios a los maltratadores y los aspectos legislativos, políticos y culturales ocupan los siguientes puestos en el ranking temático de las noticias relacionadas con la violencia de género publicadas por los diarios vascos. La abundancia de noticias sobre juicios se explica por el interés que genera en la gente todo lo relacionado con querellas, veredictos, penas, cárcel, más si a ello se le añade delitos de violencia y/o agresión sexual. Pero además, hay que tener en cuenta que, en el periodo de tiempo que se analiza en este estudio -desde septiembre del 2003 hasta junio del 2004-, la opinión pública empieza a sentir el tema de la violencia de género como un problema social, que le suscita distintas reacciones, entre ellas el deseo de que se haga algo desde las instituciones y el Gobierno para paliar el constante goteo de muertes de mujeres por actos violentos cometidos por sus parejas. Esto hace que las informaciones sobre las 
distintas acciones emprendidas contra los maltratadores cobren una importancia paralela a la que ya empiezan a tener las noticias sobre las agresiones al sexo femenino.

Lo que acontece en los meses objeto de esta investigación también justifica la profusión de noticias sobre aspectos políticos y legislativos. En ese periodo en España se produce el primer debate político acerca de la promulgación de una ley integral contra la violencia de género y comienza a dibujarse el Proyecto de Ley Orgánica de Medidas de Protección Integral contra la violencia de género. Si bien el grupo parlamentario socialista ya había presentado en el Congreso el proyecto de ley orgánica integral contra la violencia de género el 29 de diciembre del 2001, el debate sobre esta ley se acrecienta la primera mitad del 2004. El 14 de marzo de ese año se celebraban comicios generales y el PSOE había incluido en su programa el tema de la violencia de género. Esto provoca y aviva las diferencias que el PP y el PSOE pudieran tener respecto a la ley integral. Incluso su propia denominación genera diferencias. Y cuando el PSOE gana las elecciones, la aprobación de la ley se convierte en el punto fuerte de la gestión inicial socialista al frente del país, por ser una de las promesas realizadas a su electorado.

Los diarios se hacen eco en sus páginas no tanto del contenido de la ley como de los enfrentamientos verbales entre los dirigentes de los dos partidos. La controversia y el cruce de descalificaciones entre los parlamentarios, se refiera al tema que sea, siempre tienen un lugar en la agenda informativa de los diarios. Y en el tema de la violencia de género, no actúan de manera diferente. De ahí que Berria en 22 noticias, Deia en 40, El Correo en 26, El Diario Vasco en 28 y Gara en 11 informen sobre las intervenciones políticas y legislativas que provocó el Proyecto de Ley Integral de la Violencia de Género y las primeras medidas de protección que se tomaron.

La cultura y la educación resultan temas minoritarios de las noticias sobre violencia de género; apenas llegan al 5\% en todos los periódicos. Con una excepción: Berria. Este diario en el $21,7 \%$ de las noticias sobre violencia de género informa de algún acto cultural promovido para denunciar o informar de este tipo de violencia y sobre acciones educativas de sensibilización acerca de la igualdad de sexos. El tema 
religioso se asoma a la información de la violencia de género a través de la controversia suscitada por las declaraciones de los obispos de la Conferencia Episcopal quienes esgrimían, como una de las causas de las violencia de género, la libertad sexual ${ }^{2}$.

Asimismo, todos los diarios mayoritariamente informan acerca de la violencia de género en noticias de extensión inferior a un cuarto de la página. Son informaciones breves en las que se noticifica la detención de algún agresor, algunos de sus datos personales, el delito que ha cometido y contra quien. El tratamiento informativo otorgado a los casos de violencia de género se asemeja, por tanto, en muchas ocasiones, al de las noticias breves de sucesos.

En la Tabla 3 se observa como esta característica resulta especialmente significativa en el diario Gara: casi el $80 \%$ de las noticias se ajusta a esa extensión. En el resto de los periódicos, se acerca o supera el $50 \%$.

Tabla 3: Noticias cuya extensión es inferior a $1 / 4$ de la página

\begin{tabular}{|l|l|l|l|l|}
\hline BERRIA & DEIA & DV & EL CORREO & GARA \\
\hline De 171 & De 263 & De 207 & De 196 & De 188 \\
$112(65,5 \%)$ & $145(55,1 \%)$ & $120(58 \%)$ & $93(47,4 \%)$ & $147(78,19 \%)$ \\
\hline
\end{tabular}

Tal y como se acaba de exponer, la gran mayoría de las noticias publicadas en la prensa vasca sobre violencia de género se refiere a episodios de maltrato y a la posterior detención de los causantes de tales agresiones.

La publicación de estos hechos, tal y como constata, entre otros, el libro titulado La violencia doméstica. Informe sobre los Malos Tratos a Mujeres en España, ha roto la espiral de silencio que existía respecto a la violencia de género; ha acercado a los ciudadanos la grave dimensión de este tipo de violencia y ha jugado un papel importante

\footnotetext{
${ }^{2}$ Vid., por ejemplo, "La Conferencia Episcopal Española culpa del maltrato a la "revolución sexual de los 60" en Gara, pág. 3, enero 2004. "Duras críticas a las posturas de los obispos sobre la violencia de género", Deia, 4 de febrero, 2004.
} 
en la toma de conciencia acerca de este tema. En parte por la acción de los medios, por tanto, la violencia de género ha pasado a considerarse una cuestión social que no sólo concierne a la pareja: compete a diversas autoridades y organismos y debe involucrar, en distinta medida, a toda la sociedad. Este es un primer paso importante para su erradicación. No obstante, la preponderancia de las noticias sobre violencia de género que informan sobre actos violentos puntuales, sobre todo con resultado de muerte, puede contribuir a que la opinión pública olvide que la mujer sufre esta violencia de forma continuada y que, además de la violencia física, puede ser víctima también de violencia psíquica y/o sexual por parte de sus parejas. Puede ayudar a que desaparezca la visión del ambiente cotidiano de violencia y de vejación constante en el que viven las mujeres maltratadas y a ocultar su carácter estructural. Tal y como constata José Luis Dader, las mujeres sean para las noticias una nueva modalidad de suceso o accidente. Sin embargo, tal y como afirma Pilar López Díez, "la violencia contra las mujeres no puede considerarse un suceso aislado que, como un accidente de coche, hay que dar cuenta de él cada vez que se produzca la muerte de una mujer e indagar en cada caso "la" razón de tanta violencia" (2002: 30). La violencia de género no es un hecho puntual motivado por el alcoholismo, los celos, el estrés o la pasión incontrolada, es decir, algo excepcional cuya causa haya que buscar en la vida personal y en lo problemas individuales de cada maltratador. López Díez, de forma muy clara y convincente, argumenta que

Al tratar de explicar el porqué de la acción violenta, se recurre al estereotipo como el argumento más simple (alcoholismo, celos, crimen pasional, delincuencia, problemas psicológicos y otros) cuando la más básica regla del razonamiento podría invertir el papel de agresor y víctima, y dar al traste con el estereotipo: ¿por qué las mujeres a pesar de los celos, del estrés, de los problemas psicológicos, la depresión o de cualquier otra razón que explica para la profesión periodística las razones de los agresores, tienen índices de agresión mucho más bajos que ellos? (26).

La violencia de género, como apunta el libro titulado Mujer, violencia y medios de comunicación. Dossier de prensa, "constituye un grave problema social que presenta 
profundas raíces sociales, ideológicas y culturales" (2002: 8); se trata de un problema estructural que requiere modificaciones sustanciales en los comportamientos, actitudes y valores de hombres y mujeres como repetidamente apunta Pilar López Díaz. Es una violencia en la que el género del agresor y el de la víctima va íntimamente unido a la explicación de dicha violencia.

Hay muchas agresiones y formas de violencia que no guardan relación con el hecho de ser hombre o mujer mientras que la que denominamos de género es la que ejercen los hombres para mantener el control y el dominio sobre las mujeres,. La violencia se deriva de la desigualdad entre hombres y mujeres y se hace necesaria para mantener a estas últimas en situación de inferioridad. Reducirla a un mero hecho aislado de violencia supone no ahondar en su especificidad y, por consiguiente, no se colabora en su futura erradicación y, principalmente, en la progresiva toma de conciencia de que, para prevenirla y eliminarla, hay que conseguir la igualdad entre sexos. Como explica Ana $\mathrm{Carcedo}^{3}$, la violencia de género se debe conceptualizar en dos palabras: problema de poder.

\section{Análisis de titulares}

A continuación se aborda el análisis cuantitativo y cualitativo del corpus propiamente dicho a través del análisis de titulares de noticias, reportajes y entrevistas y editoriales y artículos de opinión. Por medio de estos capítulos se obtiene una visión completa del tratamiento de la violencia de género a través de los diversos géneros periodísticos de los diarios seleccionados. El capítulo centrado en el análisis de titulares refleja un aspecto esencial del estudio del tratamiento informativo de la violencia de género en la prensa, y complementa tanto los análisis cuantitativos de noticias según géneros y temas como el cualitativo de artículos de opinión y editoriales.

${ }^{3}$ Vid. CARCEDO CABAÑAS, Ana: Violencia contra las mujeres, un problema de poder, http//www.isis.cl/temas/vi/reflex17.htm 
Se estructura el análisis a partir de las aportaciones de Teun Van Dijk, según las cuales la temática informativa se organiza mediante esquemas o superestructuras específicas relativas a las noticias, entre las que destacan los titulares y la cabecera, que juntos pueden clasificarse como un sumario. Otras categorías son los sucesos principales, los artículos de fondo (historia y contexto), las reacciones verbales (las declaraciones) y los comentarios (valoración y predicción). Añade este autor que las categorías obligatorias son el titular y los sucesos principales, mientras que las restantes son opcionales y tienden a aparecer en noticias más extensas. Y es que el titular hay que entenderlo como la macroestructura textual que fundamenta el sentido de la noticia. Partiendo de estas afirmaciones, el análisis que proponemos se centra en el titular como elemento esencial en la función informativa ya que la información que añade el texto informativo rara vez resulta imprescindible para comprender el sentido de la noticia.

Nuestro análisis de los titulares responde a una doble aproximación. Por una parte, arrancamos de los estudios tradicionales sobre morfología del titular: clasificación de titulares dependiendo de la sección, el tema y el impacto, aspectos lingüísticos y sintácticos esenciales para entender el significado en su totalidad.

Pero, por otra, también se incide en aspectos semántico-ideológicos siguiendo los planteamientos de Van Dijk, más próximo al estudio en términos culturales, ya que no sólo es importante analizar lo que se dice en el titular, sino también lo que se calla, lo que se obvia, se omite de forma deliberada o no, así como la ubicación del titular respecto de otras noticias. En realidad, el resultado de nuestra investigación responde a un análisis crítico de titulares.

El capítulo se divide en un análisis pragmático lingüístico de titulares, que de modo exhaustivo se detiene en las formulaciones utilizadas por los diversos diarios y en un análisis contrastivo de titulares, en el que se seleccionan algunos de los casos más representativos para establecer una comparación contrastada. $\mathrm{Si}$ nos atenemos al fenómeno en sí, se constata que la atención prestada por los medios de comunicación a la violencia de género ha ido en aumento en los últimos años. Esto no nos sorprende si tenemos en cuenta que la cantidad de casos registrados, denunciados y de mujeres 
asesinadas en los últimos años a manos de sus parejas ha ido en un aumento exponencial. Aunque cantidad informativa no siempre es igual a calidad - particularmente en estos casos, en los que la prensa y los medios en general han abusado de la presencia de estos asesinatos con fines sensacionalistas-, hemos podido comprobar felizmente que muchos de los problemas que afloraban en los estudios iniciales de principios y mediados de los 90 sobre violencia de género y que estos estudios denunciaban son ya historia.

En este sentido merece la pena poner de manifiesto los datos obtenidos por estos estudios previos y contrastar tanto los planteamientos de partida como el desplazamiento de la mirada hacia los malos tratos en el corto espacio de dos años (Pilar López, 2002). Cuestiones reivindicadas o criticadas por estudios previos pueden estar ya superadas en 2005 y, por supuesto, con planteamientos iniciales que actualmente ya están superados. El ejemplo más claro y obvio es que ya nadie se atreve a denominar "crimen pasional" al asesinato de una mujer a manos de su pareja o ex-pareja y muy pocos lo siguen considerando un asunto "privado".

El número de noticias que han aparecido en la prensa vasca relacionadas con las agresiones y condenas, en el periodo de tiempo que hemos abarcado (septiembre 2003-junio 2004, ambos inclusive), tiene valor en la medida en que se puede ver el interés de los distintos diarios por sacar a la luz el problema.

Por otra parte, el ámbito que abarca cada diario (noticias de ámbito nacional / noticias de ámbito local) y el concepto que tenga de ámbito (nacional = España) / nacional $=$ Euskal Herria) aporta información complementaria.

En cuanto al número de noticias de esta clase, en principio observamos que el número no es similar en todas las publicaciones: 


\begin{tabular}{|l|l|l|l|}
\hline Periódicos/Temas & Delitos y detenciones & Juicios y condenas & Total \\
\hline Berría & 68 & 30 & 98 \\
\hline Gara & 94 & 41 & 95 \\
\hline Deia & 124 & 35 & 159 \\
\hline EI Diario Vasco & 104 & 45 & 149 \\
\hline EI Correo & 111 & 28 & 139 \\
\hline
\end{tabular}

Tras lo dicho hasta ahora, se puede concluir que, si bien presentando diferencias en cuanto al ámbito abarcado, toda la prensa vasca sigue la política de recoger de forma constante los casos de violencia de género, lo cual es indicativo de una mayor conciencia de los medios del problema de la violencia contra la mujer. De todos modos, el hecho de que la mayor parte de este tipo de noticias se recojan, dentro de la sección, en apartados (por ejemplo, el de "Ciudadanos" en El Correo y El Diario Vasco) donde se ubican frecuentemente junto a las noticias de sucesos locales (accidentes, robos, agresiones, detenciones, etc) muestra el valor relativo que les otorgan estos diarios la mayoría de las veces. En este punto es interesante avanzar que las noticias sobre violencia contra las mujeres no sólo comparten espacio con el resto de "Sucesos": robos, accidentes, altercados callejeros, etc., sino que también comparten lenguaje. La formulación de un titular breve que hace referencia a un robo menor, a un episodio de violencia callejera o a un caso de violencia de género es prácticamente idéntica. Aunque este tema será desarrollado más abajo al tratar específicamente de aspectos pragmalingüísticos, resulta conveniente vincularlo con la ubicación. Las noticias sobre violencia de género no solo comparten espacio y lenguaje con el resto de delitos y sucesos, también provienen la mayor parte de ellas de las mismas fuentes policiales y judiciales, lo que lleva a los diarios a agruparlas, no sabemos si de forma un tanto irreflexiva, en la misma sección, con formato semejante (sobre todo en el caso de "breves") y sin elaborar la información que también con toda probabilidad viene ya 
redactada de las notas de prensa de la institución pertinente (Policía, Ertzaintza, Guardia Civil, Juzgados, etc.). Los efectos de esta ubicación pueden ser negativos al categorizar los delitos de violencia contra las mujeres como delitos comunes y aislados, pues se ignora la dimensión social y cultural de estas agresiones. En efecto, una mirada superficial a las noticias recogidas es suficiente para afirmar que la mayor parte de ellas aparecen como breves y con una cobertura muy limitada. Sólo cuando la noticia salta a primera página ( $\mathrm{y}$ tal como hemos visto, pocos son los casos que ocupan un lugar en la "Portada": Berria, 1; Gara, 2; Deia, 3; El Correo, 5, y El Diario Vasco, ninguno) ) u ocupa un espacio considerable dentro de la página, el tratamiento varía y la noticia se desarrolla de forma más elaborada y compleja.

Tal como se afirma en el dossier publicado por RTVE sobre Mujer, Violencia y Medios de comunicación, "las normas tipográficas o de estilo de los diferentes medios obligan a veces a titular de manera tan esquemática que resulta difícil transmitir los distintos matices de hecho en tan pocas palabras" (2002: 9). Ciertamente, si esto es aplicable a todos los titulares de prensa, lo es especialmente a los de las noticias breves.

Las consecuencias, por otra parte, se hacen visibles en que la síntesis puede no sólo provocar una pérdida de matices, sino también el riesgo de caer en la rutina, con lo que ello conlleva de repetición de esquemas y pérdida de sensibilidad ante el problema de la violencia contra las mujeres.

Esta rutina que Pilar López explica como meras cuestiones de normativa en los medios al intentar dar la mayor información en el menor espacio posible, también se explica como resultado de ese proceso de "reproducción" del discurso que apuntábamos un poco más arriba: la información se resume, se selecciona o meramente de reproduce de los discursos originales, generando así titulares casi clónicos que llevan al cansancio y a la postre, a cierta trivialización de la noticia.

En nuestro corpus, los modelos se repiten invariablemente, con las excepciones de ciertas noticias de agresiones que tienen una cobertura informativa mayor al tratarse de sucesos de mayor impacto social. De esta uniformidad dan cuenta las tres formas 
básicas con que se inician la mayor parte de los títulos de las noticias sobre agresiones y detenciones:

- los que empiezan con los participios "detenido", "arrestado", o con la variante que introduce un número: "dos, tres, cuatro... detenidos"...

- los que comienzan con un verbo en forma personal: "agrede", "mata", "apuñala", "incendia"...; "muere"; "investigan, buscan, detienen"...

- los que se inician mencionando al agresor o a la víctima: "un hombre", "un anciano", "una mujer", "un ecuatoriano"...

Y también en lo que se refiere a los titulares sobre seguimientos de juicios y penas, los esquemas más frecuentes son los siguientes:

- los que comienzan con los participios "condenado", "absuelto" o "exculpado"

- los que contienen un numeral, que se inician con "piden $+7,12 \ldots$ años" o directamente con un numeral: "'veinte años, siete años..." (muy frecuente en Berria: Zortzi urteko kartzela zigorra tratu txarrak eta bortxaketagatik; $\underline{17}$ urteko zigorra bete beharko du emaztea hiltzeagatik), y que se refieren a los años de condena del agresor

- los que se inician con un verbo en forma personal: "sale", "ingresa", "pidió"...; "piden" (ya visto antes con los numerales), "absuelven", "rebajan"...

- los que se abren con un sustantivo: "la Policía", "el CGPJ", "el Supremo", "el jurado", "Epaimahaiak"...

Siguiendo a Van Dijk (2003: 249), podemos afirmar que, aunque la prensa en muchas ocasiones "puede ser excusada" en el tratamiento que se hace del tema porque toma sus informaciones de fuentes institucionales en los casos de sucesos informativos rutinarios (noticias breves), la utilización de las citas es una propiedad discursiva de la información que está controlada por la propia prensa (que, de aparecer, generalmente lo hacen en las noticias largas). 
La reproducción de palabras textuales no es un recurso frecuente en los titulares de las noticias relacionadas con la violencia de género. Ciertamente, si comparamos con otros tipos de informaciones (valga citar las relacionadas con temas políticos de actualidad en las que es frecuente que aparezca una frase o un sintagma pronunciados por un político), vemos que esta práctica es prácticamente inusual.

La explicación más evidente es que lo que es noticia no son las declaraciones de este o aquel, sino las acciones en si (los hechos de agresiones y condenas), y que con la reproducción de tales tipos de manifestaciones se puede condicionar la percepción que pueda tener el lector del suceso. Con esta presencia se desvía la atención del hecho en sí (que es lo que cuenta) hacia una percepción parcial (si no subjetiva) de este.

En los ejemplos recogidos, tenemos en cuenta a quién se le permite expresar su opinión y por qué (ejemplo, protagonistas que son considerados más importantes y creíbles para ser citados en relación con una noticia) y si hay alguna valoración por parte del/la periodista de la opinión que se expresa (Van Dijk, 1993/2003: 245 y ss.).

Por otra parte, antes de adentrarnos en los ejemplos hemos de exponer brevemente la problemática del discurso referido, que trata de las distintas maneras de representar las palabras que atribuyen a instancias distintas del locutor. En nuestros textos, de entre las distintas formas de cita, encontramos dos: el estilo directo y el indirecto. En cuanto al primero, la forma de expresión más habitual es el entrecomillado; para el segundo, es el uso de un verbo dicendi seguido de la conjunción "que" la forma de expresión:

"Estoy en contra de pegar a las mujeres" (declaración del Imán de Funegirola, El Diario Vasco 10-12-2003)

La madre de Cantat dice que está "como muerto" (Deia, 23-4-2004)

Un ertzaina dice que el acusado de matar a su ex mujer en Getxo declaró "en perfecto estado" (El Correo, 29-10-2003)

Emaztea ez zuela hil dio Getxoko kasuan auziperatuak (Berria, 28-10-2003) 
Ahora bien, también existe la posibilidad del estilo directo con "que", "frecuente en la prensa escrita contemporánea" (P. Charaudeau y D. Maingueneau, 2002/2005: 186):

La mujer acusada de matar a su marido de una puñalada dice que "fue un accidente" (El Correo, 5-2-2004)

Finalmente, se dejan oír las voces de otras maneras, bien utilizando la estructura "según fulanito", bien introduciendo la voz en una oración causal donde estaría omitido un verbo dicendi:

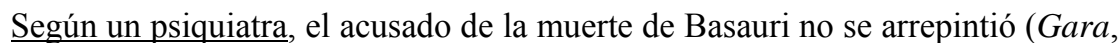
6-5-2004)

El acusado de Basauri mostró "nulo arrepentimiento" ante un psiquiatra (Deia, 6-5-2004)

Atenúan la pena a un hombre que rompió dos dientes a su compañera porque [dice, dicen que] tenía caries (El Correo, 12-5-2004)

Pasando al análisis de contenido, lo primera diferencia que observamos es que en los diarios Gara y Berria cuando recurren a "otras voces" marcan su preferencia por dejar hablar a especialistas en la materia.

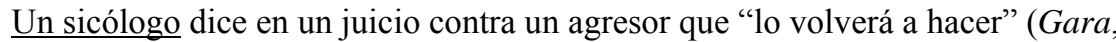
20-2-2004)

Elorrioko Udalak "aho batez" gaitzetsi du duela astebete gertatutakoa (Berria, 19-5-2004)

Estas voces de autoridad también estarían presentes en titulares de El Correo aunque, como veremos, este diario también se hace eco ampliamente de discursos diferidos que se desplazan hacia las voces de los protagonistas (agresor y víctima) de la noticia: 
Un ertzaina dice que el acusado de matar a su ex mujer en Getxo declaró "en perfecto estado" (El Correo, 29-10-2003)

Los jueces achacan a un "fallo policial" la última muerte por violencia doméstica (El Correo, 2-4-2004)

La jueza decana de Barcelona alerta contra las denuncias de malos tratos "falsas o infladas" (El Correo, 28-5-2004)

El Poder Judicial teme que la polémica por los falsos malos tratos "desanime a las víctimas" (El Correo, 29-5-2004)

Cuando se deja hablar al agresor, la víctima o a algún testigo, tanto en Gara como en Berria se hace evitando dar lugar a un titular sensacionalista. Por ejemplo, cuando se da la palabra al agresor es para dejarle pronunciarse en torno a su inocencia:

Berak erail zituela aitortu du 37 urteko senarrak (Gara, 17-2-2004)

Solo encontramos un par de titulares en que se alude a la causa de la agresión recurriendo a otra voz. En uno - aparecido en Berria- es el agresor, una familia turca, que afirma haber matado a su hija en nombre del "honor". Sin duda, el diario está subrayando la diferencia cultural que supone en este caso mentar el "honor" como causa:

Turkiako familia batek alaba hil du, "ohorearen izenean" (Berria, 29-4-2004)

En el otro, estamos ante un ejemplo de las mismas características aparecido en Gara, en el que ya sin necesidad de esa distancia cultural se subraya la presencia con valores similares en nuestra propia sociedad:

Condenado por pegar a una amiga a la que [dice, dicen que] exigía que le fuera fiel (Gara, 6/06/2004)

Estos dos son los únicos casos en los que en estos periódicos se alude a la justificación de la agresión y creemos que su finalidad no es de tipo sensacionalista, 
sino la de denunciar este tipo de valores que discriminan a la mujer y que deberían estar desterrados de nuestras sociedades.

En estos dos periódicos, además, la tónica general es la de identificar la fuente en el mismo titular sin dar cabida a la ambigüedad del origen de la voz, es decir, sin que no quepa la menor duda de quién ha dicho eso, tal como se puede comprobar en casi todos los ejemplos citados anteriormente.

En el caso de El Correo y Diario Vasco nos encontramos con citas textuales referidas, sobre todo, a extractos de la sentencia de condena:

21 meses de cárcel por "violencia extrema" (El Diario Vasco, 22-12-2003)

Diez años de cárcel para una mujer que mató a su marido "en represalia" por sus malos tratos (El Diario Vasco, 19-12-2003)

Condenan a un hombre a 17 años por matar "con alevosía" a su pareja en Basauri (El Correo, 20-5-2004)

Si nos centramos en estos últimos y en Deia, observamos que proliferan los titulares en que, además de preferirse la voz del agresor, de la víctima o de algún testigo a la de los especialistas, resulta difícil — si no imposible — identificar la fuente. Están, por otra parte, dotados de un carácter sensacionalista que hace que la atención se desvíe de la gravedad del hecho hacia los detalles que pueden alimentar el morbo de los lectores. Veamos algunas de estas "perlas":

Amenaza a su mujer "cansado de escucharla gritar" (Deia, 16-4-2004) La apuñaló porque "se lo ordenó el demonio" (El Diario Vasco 12-5-2004)

"Cuando me pegaba me tapaba la tripa para que no hiciera daño al bebé" ( $E l$ Diario Vasco 26-11-2003)

Piden 15 años por darle un hachazo, porque roncaba (El Diario Vasco 14-122003)

Creía que estaba "casi bien" matar a su mujer (El Diario Vasco, 6-5-2004).

"Nada más denunciarle, le llenó el cuerpo de cuchilladas" (El Diario Vasco, 41-2004)

Violó a su ex novia por depilarse el pubis (El Diario Vasco 28-2-2004)

"Estaban llenos de sangre" (El Correo, 29-4-2004) 
"A veces le pegaba alguna bofetada en la cara, como cualquier otra pareja" (El Correo, 28-10-2003)

Atenúan la pena a un hombre que rompió dos dientes a su compañera porque tenía caries (El Correo, 12-5-2004)

Finalmente, presentamos una misma noticia formulada de forma diferente en el titular de los periódicos Deia y El Diario Vasco, con cita textual y sin ella, respectivamente:

El CGPJ defiende al juez que valoró la ropa de la víctima en un caso de malos tratos (Deia, 22-1-2004)

El CGPJ respalda al juez que absolvió a un acusado de malos tratos porque la víctima "iba a la moda" (El Diario Vasco, 22-1-2004)

Merece particular atención este ejemplo porque ilustra el valor de la cita textual en muchos de los casos que analizamos. Sin duda alguna, la noticia tal y como se articula en El Diario Vasco es mucho más impactante que el titular aparecido en Deia. ¿Qué es noticia en un caso y en otro? ¿La actitud del CGPJ de defensa de uno de sus funcionarios, o la falta de ecuanimidad de un juez a la hora de juzgar a un presunto maltratador? En el caso de Deia parece que la noticia se centra en el corporativismo que muestra el CGPJ al cerrar filas en torno a un juez polémico, sin especificar de una forma clara a qué se debe la polémica suscitada por dicho juez. En el Diario Vasco, sin embargo, la información que resalta precisamente es la cita textual, el entrecomillado, dando a entender de forma implícita que la decisión del CGPJ de defender a dicho juez es, a todas luces, muy cuestionable, porque lo que es cuestionable es la decisión del propio juez. Mientras que Deia utiliza el término "valoró" resumiendo de esta forma la actitud del juez, el Diario proporciona una información más detallada estableciendo una relación causal con la cita textual "porque la víctima "iba a la moda" que hace que el centro de atención de la noticia se desplace hacia esta cita, con el riesgo de frivolizar la sentencia judicial al reducirla a este detalle, pero también denunciando el hecho de forma más expresiva mediante expresión coloquial. El impacto que una y otra formulación pueden tener en el público lector es diferente: una pasaría sin duda más 
desapercibida, mientras que la otra arrancaría más de una exclamación o gesto de escándalo, introduciendo un elemento emocional en la interpretación de la noticia. Estaríamos frente a lo que Ladevéze denomina un titular apelativo (1991: 221), cuyo objeto no es tanto informar de algo como llamar la atención sobre un hecho. La cuestión que se plantea seguidamente es la idoneidad de uno u otro titular para informar sobre la violencia de género. ¿Cuál es más legítimo en este caso? ¿Cuál cumple mejor su función de informar sobre una noticia relativa a violencia contra las mujeres? ¿Necesitan las noticias de agresiones o de condenas este tipo de tratamiento informativo? ¿No se cae con frecuencia en el sensacionalismo más frívolo precisamente por querer llamar la atención sobre un hecho y hacerlo foco informativo cuando lo que realmente importa es la profunda desigualdad y los prejuicios culturales que esconde? Con este tipo de titulares la prensa pone de manifiesto que hay un problema social, pero frecuentemente fracasa en su función de concienciar a la sociedad sobre las raíces profundas de dicho problema, ya que la mayor parte de las veces, estos titulares impactantes no van acompañados de una reflexión seria y ecuánime.

A la luz de todo lo expuesto arriba, parece evidente que la forma de presentar las noticias sobre violencia de género en titulares refleja una notable diferencia entre los diarios Gara y Berria, por una parte, y El Correo, Deia y Diario Vasco, por otra. Si bien los primeros recogen menos noticias de agresiones a mujeres, limitando el ámbito de información a los territorios vascos, también es cierto que su tratamiento informativo de este fenómeno sigue pautas más acordes con lo que entendemos ha de ser el tratamiento en los medios de esta forma de violencia, huyendo del sensacionalismo y del titular fácil y morboso y evitando hacer trivial la noticia. Los titulares con citas textuales que no añaden información sino que llaman la atención de una forma morbosa sobre el acto de violencia entendemos que no ayudan a la concienciación social sobre este fenómeno. Lo mismo pasaría con aquellos titulares en los que la atención se desplaza del hecho de que una mujer ha sido agredida debido a la violencia machista, a la forma de agresión (hachazos, puñaladas, degüello, navajazos, martillazos...), ya que estos detalles solo contribuyen a aumentar el morbo y el sensacionalismo en torno a este 
tipo de agresiones. La ubicación de estas noticias y su formulación como hechos vinculados al ámbito de "Sucesos" "Accidentes" y demás tampoco contribuye de forma positiva a dar visibilidad y a denunciar la violencia contra las mujeres como un problema social de primera magnitud al que subyacen profundas razones culturales que hay que abordar desde los medios a través de una información veraz y digna y la educación y concienciación de la ciudadanía.

\section{Entrevistas y reportajes}

El siguiente apartado es el dedicado a las entrevistas y reportajes. Los textos interpretativos suponen un $16 \%$ del material publicado sobre violencia de género por los diarios vascos en el periodo de estudio de esta investigación. Este dato no resulta sorprendente ni exclusivo del tema que abordamos sino acorde con la labor periodística. La realización de entrevistas y reportajes se suscita después de que se produzcan hechos relacionados con la violencia de género, de los que el diario informa a través de las noticias. Resulta lógico dentro del quehacer profesional, por tanto, como se expondrá en la primera parte de este capítulo, que el género más común para informar sobre el maltrato a las mujeres sea la noticia. Y que los sucesos recogidos en ellas provoquen por parte del diario el interés por realizar entrevistas o reportajes relacionados con esos hechos.

No obstante, si bien la preponderancia de las noticias sobre las demás tipologías textuales resulta justificada, se considera plausible que los diarios aborden la violencia de género fuera del reducto de la información de actualidad inmediata. Las razones por las que aproximarse a la realidad del maltrato a la mujer a través de entrevistas y reportajes resulta positivo se relacionan directamente con las características de estos textos periodísticos y de la propia violencia de género. Si bien la violencia de género irrumpe mayoritariamente en las páginas de los diarios a través de noticias sobre agresiones cometidas por los maltratadores y sobre su detención, la aproximación a la realidad de los malos tratos hacia las mujeres desde los géneros interpretativos de la 
entrevista y el reportaje constituye una práctica profesional plausible y eficaz para el conocimiento real del problema y su progresiva desaparición. Ambos géneros periodísticos poseen características idóneas para ello y, a su vez, se adecuan a los requisitos que las propias características de la violencia de género imponen para su información.

En primer lugar, ni el reportaje ni la entrevista están ligados con la actualidad inmediata. La comprensión de un tema tan complejo como el del la violencia de género requiere que en las páginas de los diarios se editen también temas de interés no relacionados sólo con los hechos ocurridos el día anterior. La entrevista y el reportaje permiten a los/as profesionales ahondar en las causas, consecuencias y posibles acciones en contra del maltrato y ofrecer a los/as lectores/as una mayor reflexión y análisis de los acontecido que la que proporcionan los datos y las estadísticas sobre las mujeres maltratadas y/o asesinadas. Asimismo los diarios a través de estos géneros pueden tener una actuación muy positiva en la concienciación social de que la igualdad de sexos es el paso prioritario y primero en la prevención y eliminación de la violencia de género. Además de denunciar el síntoma -violencia contra la mujer- a través de la publicación de noticias sobre hechos de maltrato, los/as profesionales pueden lograr permear mentes, prácticas y costumbres. Asimismo, la extensión del reportaje y la entrevista, la necesidad de acudir a diversas fuentes para su elaboración y la amplitud de temas que pueden abordar hacen de estos géneros resultan idóneos para abordar el tema de la violencia de género.

\section{Periodismo de opinión}

El último apartado se centra en el análisis del llamado periodismo de opinión del corpus seleccionado, e incluye los editoriales, artículos de opinión, columnas, cartas al director y viñetas. La mayoría de los/as críticos/as insisten en la necesidad de subrayar el componente marcadamente personal, con carácter persuasivo y alejado de la neutralidad de este tipo de escritos. El análisis de los editoriales, artículos de opinión, 
columnas, cartas al director y viñetas seleccionados parte necesariamente de las definiciones de discurso crítico, ya que será el modelo seleccionado para su aplicación al corpus existente, y del término violencia de género, base semántica sustancial para este estudio.

Para entender el término discurso en sentido amplio se parte de una primera definición general proporcionada por Teun van Dijk de discurso como evento comunicativo específico dentro un tipo de análisis orientado socialmente. En la práctica cotidiana de los estudios del discurso se restringe esta definición y pasa a utilizarse el término para referirse al producto logrado o en desarrollo del acto comunicativo, es decir, a su resultado escrito o auditivo tal como aparece a disposición de los/as receptores/as para su interpretación. El análisis del discurso no puede realizarse fuera de su contexto histórico, social, político y cultural, y en lo referente a la postura ética e ideológica que caracteriza al presente estudio, es preciso señalar que se enmarca en la definición que el propio Teun van Dijk (1997), proporciona de análisis crítico. Tal es, en efecto, el espíritu que guía la redacción de este capítulo.

Desde una posición feminista de compromiso con los derechos de las mujeres, se trata de analizar críticamente el periodismo de opinión en el corpus de estudio con el ánimo de alentar las buenas prácticas ya existentes y de alertar acerca de posibles inconsistencias en el tratamiento recibido. El estudio se centra en la exploración detallada de las siguientes hipótesis de trabajo: primera, el tratamiento se aproxima a las buenas prácticas recomendadas por las investigaciones sobre la violencia de género. En el periodismo de opinión no se busca la explicación singular de cada caso de maltrato, sino que se expone el problema conjuntamente y se exploran las soluciones que deben aplicarse. No obstante, en un número reducido de casos se llega a situar el problema en el contexto de la construcción de género y poder. La causa principal de los malos tratos es la desigual distribución del poder entre mujeres y hombres que existe en la sociedad, pero ello no se constata todavía con la fuerza suficiente. 
La segunda hipótesis que se aborda es la desigual distribución social del poder es expuesta y desarrollada con conocimiento y espíritu crítico en los artículos periodísticos de mujeres especializadas en investigaciones y programas feministas.

Seguidamente se constata cómo el género iconográfico, tal y como aparece en el corpus analizado, se presenta como un modo definido por un planteamiento lúcido y crítico del problema y por una alta eficacia en su exposición condensada y directa. Asimismo, el corpus analizado refleja en ocasiones una atención por parte de los medios de comunicación a los esfuerzos encaminados a acallar a quienes denuncian y exponen la violencia de género, así como a quienes de algún modo la justifican. Si bien las opiniones se posicionan por lo general abiertamente en contra de tales ideas y prácticas, no deja de ser indicativo de que los ejemplos negativos reciben un amplio tratamiento.

Lo último que se constata en este capítulo es que existe una enorme diversidad en los periódicos en cuanto a sus posiciones políticas e ideológicas, en cuanto al tratamiento del problema y en cuanto a los niveles de compromiso con la defensa de los derechos de las mujeres.

En resumen, distintos tratamientos dentro de unas prácticas periodísticas que en los apartados de opinión cada vez se acercan más a los protocolos y recomendaciones que diversos estudios e investigaciones proponen como positivas en el tratamiento de la violencia de género. Queda aún mucho camino por recorrer, pero la prensa vasca se muestra puntera en las secciones de opinión en el marco del periodismo del Estado español, y su carácter marcadamente progresista contribuye decididamente y con valentía a la sensibilización social y a la reflexión personal.

\section{Conclusiones}

El estudio constata que la violencia de género constituye una preocupación clara por un tema que hasta hace tan solo unos años era inexistente. La publicación continuada de actos de violencia contra las mujeres ha roto la espiral de silencio que existía sobre este tipo de agresiones y ha acercado a la ciudadanía la grave dimensión 
del problema. La prensa desempeña, de este modo, un importante papel en la toma de conciencia de la opinión pública y de las instituciones. Dicho esto, se constata que el tratamiento mayoritario que la prensa vasca otorga al tema de la violencia de género es fundamentalmente informativo ( $76 \%$ frente al restante $24 \%$ interpretativo y de opinión), y se asemeja al de sucesos. La ubicación y formulación de noticias de violencia contra las mujeres como hechos vinculados a las categorías de Sucesos o de Accidentes no contribuye de forma positiva a visibilizar y denunciar esta forma de violencia como un problema de primera magnitud con arraigadas desigualdades sociales y culturales subyacentes. Por el contrario, se debe apostar por la inclusión de reportajes y entrevistas desarrollados en profundidad, con presencia de expertas en el tema tratado y con al progresiva formación de los/las periodistas a quienes se adjudican este tipo de informaciones. En lo referente a los géneros interpretativos y de opinión, se observa en editoriales, artículos, columnas, viñetas y cartas una seria preocupación por el tema y una decidida apuesta por la concienciación social y política, con lo que se avanza en el reconocimiento de las desigualdades de poder existentes entre hombres y mujeres. Queda mucho camino por recorrer, pero ya se han dado pasos importantes. El carácter progresista de la prensa vasca ayuda a una buena disposición frente a los problemas sociales y los medios de comunicación debe contribuir poderosamente a favorecer una situación más justa desde la reflexión social. 


\section{BibliografíA}

ABRIL VARGAS, N. (1999): Periodismo de opinión. Madrid, Síntesis.

AIERBE, P. y otros (2003): Análisis de prensa 2002. Inmigración, racismo y xenofobia, San Sebastián, Mugak.

ALBERDI, I. y MATAS, N. (2002): La violencia doméstica. Informe sobre los malos tratos a mujeres en España, Colección Estudios Sociales, $n^{\circ} 10$, Fundación La Caixa. ANDRÉS CASTELLANOS, S. de. “¿Violencia de género?” en VIGARA TAUSTE, A.M. y JIMÉNEZ CATALÁN, R.M. (eds.) (2002): Género, sexo, discurso. Madrid, Laberinto. 21-45.

CHARAUDEAU, P. y MAINGUENEAU, D. (2002/2005): Diccionario de análisis del discurso, Madrid, Amorrortu ( $1^{\mathrm{a}}$ ed. en francés, 2002).

DADER, J.L. (2000): La “mujer” como categoría emergente en la producción de noticias: pros y contras de una nueva visibilidad periodística. Ponencia presentada en la Jornada sobre "Mujeres, Hombres y Medios de Comunicación" de la Dirección General de la Mujer, Junta Castilla y León. Valladolid, 23 de noviembre de 2000.

EL PAÍS (2002): “Elementos de titulación”, Libro de estilo, Madrid, Santillana, pp. 4755.

ESCANDELL VIDAL, M.V. ((1996/2002): Introducción a la pragmática, Barcelona, Ariel.

FAGOAGA, C. (1994): Comunicando violencia contra las mujeres. Estudio sobre el lenguaje periodístico. Madrid, Universidad Complutense.

FERNÁNDEZ DÍAZ, N. (2003): La violencia sexual y su representación en la prensa, Barcelona, Anthropos.

FUENTES RODRÍGUEZ, C. (2000): Lingüística pragmática y análisis del discurso, Madrid, Arco/Libros. 
Tratamiento de la violencia de género en la prensa vasca

KITZINGER, J. "Media Coverage of Sexual Violence Against Women and Children", en ROSS, K. y BYERLY, C. (2004): Women and Media. International Perspectives. Oxford, Blackwell. 13-38.

LEÓN GROSS, T. (1996): El artículo de opinión. Barcelona, Ariel.

LLERA, J.A. (2003): El humor verbal y visual de La Codorniz. Madrid, CSIC.

LÓPEZ DÍAZ, P. (2002): Mujer, violencia y medios de comunicación, Madrid. Instituto Oficial de Radio y Televisión.

—(ed.) (2004): Manual de Información en Género, Madrid, Instituto Oficial de Radio y Televisión.

LÓPEZ GARCÍA, X. (1986/99): “A titulación”, Comunicación e información escrita. Redacción periodística, Santiago, Edicións Lea.

LOSCERTALES, F. (2003): El lenguaje publicitario: estereotipos discriminatorios que afectan a las mujeres, en Medios de Comunicación y violencia contra las mujeres, Sevilla, Instituto Andaluz de la Mujer y Fundación Audiovisual de Andalucía.

MARTÍNEZ DE SOUSA, J. (2003): "Estilo periodístico", Libro de estilo Vocento, Gijón, Ediciones Trea, pp. 31-37.

MORALES, F. (1991): Recursos de humor en el periodismo de opinión. Madrid, Universidad Complutense.

MORÁN TORRES, E. (1988): Géneros del periodismo de opinión. Crítica, comentario, columna, editorial. Pamplona, Universidad de Navarra.

NÚÑEZ LADEVÉZE, L. (1991): Manual para periodismo. Veinte lecciones sobre el contexto, el lenguaje y el texto de la información. Barcelona, Ariel.

REYES, G. (1993): Los procedimientos de cita: estilo directo y estilo indirecto, Madrid, Arco/Libros.

RTVE, grupo (2002): Tratamiento informativo de la violencia doméstica, Madrid, Instituto Oficial de Radio y Televisión.

SÁNCHEZ ARANDA, J.J., BERGANZA CONDE, R. y GARCÍA ORTEGA, C. (2003): Mujer publicada, mujer maltratada. Libro de estilo para informar en los medios de comunicación sobre la mujer, Gobierno de Navarra, Pamplona. 
VAN DIJK, T.A. (1978/1983): La ciencia del texto, Barcelona, Paidós Comunicación ( $1^{\text {a }}$ ed. en holandés, 1978).

-(1980/1990): La noticia como discurso. Comprensión, estructura y producción de la información, Barcelona, Paidós Comunicación (1. a ed. en inglés, 1980).

-(1993/2003): Racismo y discurso de las élites, Barcelona, Gedisa (1. ${ }^{a}$ ed. en inglés, 1993).

—(1997): Racismo y análisis crítico de los medios, Barcelona, Paidós. 